\title{
Kaynak Akımı Değişiminin Karbür ve Boro-karbür İçeren Kaplamalara Etkisi
}

\author{
Mustafa Kaptanoğlu* \\ Fırat Üniversitesi, Mühendislik Fakültesi, Metalurji ve Malzeme Mühendisliği Bölümü, Elazığ, Türkiye, (ORCID: 0000-0002-6295-610X), mkaptanoglu@ @irat.edu.tr
} (Illk Geliş Tarihi 03 Haziran 2020 ve Kabul Tarihi 18 Aralık 2020)

(DOI: $10.31590 /$ ejosat.747441)

ATIF/REFERENCE: Kaptanoğlu, M., (2020). Kaynak Akımı Değişiminin Karbür ve Boro-karbür İçeren Kaplamalara Etkisi. Avrupa Bilim ve Teknoloji Dergisi, (20), 827-834.

\section{$\ddot{O} \mathbf{z}$}

$\mathrm{Bu}$ çalışmada, tozaltı kaynak tekniği kullanılarak elde edilen sert dolgu kaplamalara, kaynak akımının etkisi araştırılmıştır. Bu kapsamda, 400, 450, 500 ve 550 A kaynak akımları kullanılarak kaynak testleri gerçekleştirilmiştir. Kaynak testlerinde, SAE 1020 çeliği, ferrokrom ve ferrobor tozlarını içeren seramik esaslı kaynak tozları ve S1 kaynak telinden (elektrot) yararlanılmıştır. Kaynak testleri neticesinde mikroyapı, kimyasal kompozisyon, sertlik ve aşınma gibi parametrelerde karakterizasyon işlemleri yapılmıştır. Karakterizasyon işlemleri neticesinde, genel olarak kaynak akımının artmasıyla kaplama mikroyapılarında yer alan karbür ve borokarbür faz yoğunluğunun arttığı ve kaplamalara gecen krom, karbon ve bor miktarının arttığı tespit edilmiştir. 500 A dışındaki akım değerlerinde, kaynak dikişlerinin homojenliklerinin azaldığı tespit edilmiştir. Benzer şekilde; 400 A'den 500 A'e kaynak akımının artması ile sertlik değerlerinin arttığı ve aşınma kayıplarının azaldığı tespit edilmiştir. Ancak; $550 \mathrm{~A}$ akım değerlerinde, kaplama mikroyapısında yer alan tanelerin kabalaşması nedeniyle kısmi olarak kaplamanın sertlik ve aşınma direncinin düştügü tespit edilmiştir. En yüksek sertlik değeri 61 HRC ile 500 A'de gerçekleştirilen kaynak akımı ile elde edilen kaplamada elde edilirken, en düşük sertlik değeri ise, 44 HRC ile 400 A'de gerçekleş̧irilen kaynak akımı ile elde edilen kaplamada elde edilmiştir.

Anahtar Kelimeler: Kaynak akımı, Kaplama, Karbür, Bor-karbür.

\section{Influence of Welding Current Change on Coatings Containing Carbide and Boro-carbide}

\begin{abstract}
In this study, the effect of welding current change on coatings obtained using submerged arc welding technique was investigated. In this context, welding tests were carried out using 400, 450, 500 and 550 A welding currents. In welding tests, SAE 1020 steel, ceramic-based welding powders containing ferrochromium and ferroboron powders and S1 welding wire (electrode) were used. As a result of welding tests, characterization was made in parameters such as microstructure, chemical composition, hardness and wear. As a result of the characterization processes, it was determined that with the increasing of welding current, the phase density such as carbide and boro-carbide in the coating microstructures increased and the amount of chromium, carbon and boron transition from powders to the coatings increased. At current values other than $500 \mathrm{~A}$, it was determined that the homogeneity of the weld seams decreased. Similarly; it was determined that with the increasing of welding current from 400 A to 500 A, hardness values increased and wear losses decreased. However, at $550 \mathrm{~A}$ current value, due to the coarsing of the grains in the coating microstructure, a decrease in hardness and wear resistance of coating was observed. The highest hardness value was obtained by the coating obtained by using welding current at $500 \mathrm{~A}$ with $61 \mathrm{HRC}$, while the lowest hardness value was obtained by the coating obtained by using welding current at 400 A with 44 HRC.
\end{abstract}

Keywords: Welding current, Coating, Carbide, Boro-carbide.

\footnotetext{
* Sorumlu Yazar: Mustafa Kaptanoğlu, Fırat Üniversitesi, Mühendislik Fakültesi, Metalurji ve Malzeme Mühendisliği Bölümü, Elazı̆̆, Türkiye, mkaptanoglu@ firat.edu.tr, (ORCID: 0000-0002-6295-610X),
} 


\section{Giriş}

Kaynak yöntemi kullanılarak gerçekleştirilen kaplama işlemi, bir substrat veya ana metal üzerine kaplama yapılarak, malzemelerin aşınma ve korozyon özelliklerinin geliştirilmesi işlemidir. Bu işlem, sünek bir malzeme yüzeyine sert bir yüzey kaplanması şeklinde olursa adı sert dolgu kaplama olur. Bazı durumlarda hasar gören malzeme yüzeyleri kaplama teknikleri kullanılarak eski haline getirilebilir. Bir substrat üzerine bir veya birden fazla tabaka vasitasıyla sert dolgu kaplama yapılabilmesi, kimyasal ve metalürjik gereksinimleri gerekli kılar. $\mathrm{Bu}$ gereksinimler kaynak metalinin mekanik davranışı baz alınarak hesaplanır (Oates ve Saitta, 2000).

Kaynaklı kaplama işlemleri, çeşitli teknikler kullanılarak gerçekleştirilebilmektedir. $\mathrm{Bu}$ teknikler, oksi asetilen kaynak tekniği (Civjan, Guihan ve Peterman, 2020), TIG kaynak tekniği (Shrivas, Vaidya, Khandelwal ve Vishvakarma, 2020), plazma kaynak tekniği (Köse ve Topal, 2020), özlü tel ark kaynak tekniği (Kurtulmuş, 2018), lazer kaynak tekniği (Aydın ve Karaağaç, 2019), gazaltı kaynak tekniği (Le ve Mai, 2020) ve tozaltı kaynak tekniği (Singh ve Singh, 2020a) şeklinde ifade edilebilir. Her tekniğin birbirine göre pozitif ve negatif yanları olabilmektedir. $\mathrm{Bu}$ teknikler içerisinde tozaltı kaynak tekniği, otomatik bir sistem olması, dolgu yeteneğinin fazla olmas1, kütlesel olarak iri parçaları doldurmaya uygun olması, ekonomik olması, makine kullanımının kolay olması, kaynak metalinin ve kaynak dikişinin temiz ve belirlenebilir olması ve ark ışı̆̆ının görünmemesi nedeniyle zarar veren bir 1şı̆̆a sahip olmaması gibi özellikleriyle öne çıkmaktadır. Öte yandan, tozaltı kaynak tozlarının (flaksların) sınırlı sayıda olması, tekniğin düz ve silindirik parçalarda kullanıma uygun olması ve teknikte çok yüksek 1sı girdilerinin oluşması, tekniğin dezavantajlarını oluşturmaktadır.

Literatürdeki araștırmacılar tozaltı kaynak tekniği kullanılarak gerçekleştirdikleri çalışmalarda genel olarak, kaynak parametrelerine bağlı olarak gerçekleştirilen yapay sinir ağı modellemeleri (Singh ve Singh, 2020b), kaynak flaksı üretim modellemesi ve optimizasyonu (Sharma, Kumar ve Chhibber, 2020), 1sının etkisi altında kalan alanın modellenmesi (Sailender, Suresh, Chandramohan, Venkatesh, 2020) tozaltı kaynak işlemleri sonrası kalıntı gerilimlerin hesaplanması (Suman, Biswas, Patel, Singh, Kumar ve Kuriachen, 2020) tozaltı kaynak tekniğiyle üretilen kaplamalara ilave tozların seyreltme etkisi (Srikarun, Oo, Petchsang ve Muangjunburee, 2019), tozaltı kaynak tekniği ile elde edilen niyobyumca zengin düşük alaşımlı çeliklerin TEM ve APT teknikleriyle analiz edilmesi (Liu, Xu, Shi, Kang, Procario, Hou ve Manohar, 2019) ve ferro alaşım ilavesi ile elde edilen Fe-Cr-C kaplamaların karakterizasyonu ve krom ilavesinin demir esaslı kaplamalara etkisi (Zahiri, Sundaramoorthy, Lysz ve Subramanian, 2014) gibi konulara yoğunlaşılmıştır. Görüldüğü üzere, literatürdeki çalışmalar genel olarak alaşım elementi içermeyen kaynak tozları ve kaynak telleri ile yapılan çalışmalar ile ilişkilidir. $\mathrm{Bu}$ çalışmalarda, tozaltı kaynak tekniğinin otomatik bir sistem olması nedeniyle genelde deney sonuçlarının önceden tahmini üzerine yapılan çalışmalara odaklanılmıştır (Singh ve Singh, 2020a; Singh ve Singh, 2020b; Sharma vd., 2020; Sailender vd., 2020; Suman vd., 2020). Literatürdeki eser miktardaki sert dolgu kaplama çalışmasında ise genelde alaşımsız kaynak tozu ve kaynak teli kullanımı ile birlikte yüzeye ferro alaşımların toz formda serilmesiyle kaynak metalinde yüksek sertlikler veren e-ISSN: 2148-2683 kaplamalar üzerine çalışmalar bulunmaktadır (Srikarun vd., 2019; Liu vd., 2019; Zahiri vd., 2014). Bu çalışmada ise, literatürdeki çalışmalardan farklı olarak, üretim esnasında kaynak tozu bileşenleri içerisinde ferrokrom ve ferrobor kullanılarak tozaltı kaynak tozları üretilerek, sert dolgu kaplama amaçlı kaynak testleri gerçekleştirilmiştir. Üretilen kaynak tozları ve gerçekleştirilen kaynak testleri neticesinde karbür ve boro-karbür içeren kaplamalar elde edilmiştir. İyi bilindiği üzere, kaynak parametreleri kaynak sonrası oluşan kaynak metalinin veya kaplamaların mekanik özelliklerini etkileyebilmektedir (Oates ve Saitta, 2000).

$\mathrm{Bu}$ nedenle, bu çalışmada tozaltı kaynak tekniği kullanılarak elde edilen ve karbür ve boro-karbür içeren kaplamalara kaynak akımının etkisi araştırılmıştır. Çalışmada, ferrokrom ve ferrobor tozları kullanılarak 4 farklı akım değerlerinde kaynak testleri gerçekleştirilerek optimum sertlik ve aşınma davranışı sergileyen kaplamaların elde edilmesi hedeflenmiştir.

\section{Materyal ve Metot}

\subsection{Kaynak Testlerinin Gerçekleştirilmesi}

Çalışmada gerçekleştirilen kaynak testleri Magmaweld ZD5-1000B-MZ-000BF tozaltı kaynak makinesi ve güç kaynağı ünitesiyle tamamlanmıştır. Kaynak testlerinde temel alaşım elementi geçişi amaçlı hazırlanan kaynak tozlarında \%16 ferrokrom (\% $65 \mathrm{Cr}, \% 8 \mathrm{C}$ ) ve \% 2 ferrobor (\%18 B) içeren seramik esaslı kaynak tozları kullanılmıştır. Tüm kaynak testlerinde aynı kaynak tozu kullanılmıştır. Testlerde $3.2 \mathrm{~mm}$ tel çaplı Magmaweld marka S1 olarak adlandırılan kaynak elektrodu kullanılmıştır. Substrat olarak ise 10x30x600 mm boyutlarındaki SAE 1020 çeliği kullanılmıştır. S1 elektrodu ve SAE 1020 çeliğinin kimyasal kompozisyonu Tablo 1'de verilmektedir.

Tablo 1. SAE 1020 çeliği ve S1 kaynak elektrodunun kimyasal kompozisyonu.

\begin{tabular}{ccccccc}
\hline Malzeme & \multicolumn{6}{c}{ Kimyasal kompozisyon (\% ağırlıkça) } \\
\hline SAE 1020 çeliği & $\mathrm{C}$ & $\mathrm{Si}$ & $\mathrm{Mn}$ & $\mathrm{P}$ & $\mathrm{S}$ & $\mathrm{Fe}$ \\
\cline { 2 - 6 } & 0.15 & 0.28 & 0.64 & 0.03 & 0.03 & Kalan \\
\hline Malzeme & \multicolumn{4}{c}{ Kimyasal kompozisyon (\% ağırlıç̧a) } \\
\hline $\begin{array}{c}\text { S1 kaynak } \\
\text { elektrodu }\end{array}$ & $\mathrm{C}$ & $\mathrm{Si}$ & $\mathrm{Mn}$ & \multicolumn{2}{c}{$\mathrm{Fe}$} \\
\cline { 2 - 6 } & 0.07 & 0.05 & 0.50 & Kalan \\
\hline
\end{tabular}

Kaynak testlerinde kaynak akımı hariç olmak üzere, aynı kaynak parametreleri kullanılmıştır. 1 nolu kaynak testinde 400 A akım, 2 nolu kaynak testinde 450 A, 3 nolu kaynak testinde 500 A akım ve 4 nolu kaynak testinde ise 550 A akım kullanılmıştır. Kaynak testlerinde kullanılan makine parametreleri Tablo 2' de verilmektedir.

Tablo 2. Kaplama testlerinde kullanılan makine ve ekipman parametreleri.

\begin{tabular}{ccccccc}
\hline $\begin{array}{c}\text { Kaplama } \\
\text { test } \\
\text { numunesi }\end{array}$ & $\begin{array}{c}\text { Akım } \\
(\mathbf{A})\end{array}$ & $\begin{array}{c}\text { Voltaj } \\
(\mathbf{V})\end{array}$ & $\begin{array}{c}\text { Kaynak } \\
\text { hızı } \\
(\mathbf{c m} / \mathbf{d k})\end{array}$ & $\begin{array}{c}\text { Elektrot } \\
\text { çapı } \\
(\mathbf{m m})\end{array}$ & $\begin{array}{c}\text { Polarite } \\
( \pm)\end{array}$ & $\begin{array}{c}\text { Meme } \\
\text { mesafesi } \\
(\mathbf{m m})\end{array}$ \\
\hline 1 & 400 & 28 & 50 & 3.2 & + & 32 \\
\hline 2 & 450 & 28 & 50 & 3.2 & + & 32 \\
\hline 3 & 500 & 28 & 50 & 3.2 & + & 32 \\
\hline 4 & 550 & 28 & 50 & 3.2 & + & 32 \\
\hline & & & & & &
\end{tabular}




\subsection{Mikroyapı, Kimyasal Kompozisyon ve XRD Analizleri}

Kaynak testleri neticesinde elde edilen kaplamalardan 14x10x10 mm boyutlarındaki numuneler kesilerek alınmıştır. $\mathrm{Bu}$ numuneleri mikroyapısal olarak incelemek amacıyla, numuneler metalografik numune hazırlama işlem basamaklarına tabi tutulmuştur. Bu kapsamda zımparalama, parlatma, dağlama işlemleri yapılmıştır. Dağlayıcı olarak, hacimce \% 2 nitrik asit $\left(\mathrm{HNO}_{3}\right)$ ve \% 98 etil alkolden $\left(\mathrm{C}_{2} \mathrm{H}_{5} \mathrm{OH}\right)$ oluşan nital çözeltisi kullanılmıştır. Mikroyapısal karakterizasyon işlemlerinde, Nikon Eclipse-MA200i optik mikroskobu kullanılmıştır. Mikroyapılardaki faz tayini için kaplamalardan numuneler alınarak Rigaku RadB-Dmax2 makinesinde XRD analizleri gerçekleştirilmiştir. Kimyasal kompozisyon analizlerinde ise optik emisyon spektrometresinden, Jeol marka JSM-7001F Inca X-Act model SEM-EDX ve Jeol marka JXA-8230 model EPMA-EDS makinelerinden yararlanılmıştır.

\subsection{Sertlik ve Așınma Testleri}

Sertlik testleri, Rockwell sertlik metodunun C skalasıyla ve 150 kgf'lik yükler altında EMCO marka M4U-025 model cihaz kullanılarak gerçekleştirilmiştir. Bu kapsamda, 12 farklı kaplama noktasından alınan sertlik sonuçlarının ortalaması alınarak sertlik sonuçları tespit edilmiştir. Aşınma testlerinde pin-on-belt aşınma mekanizmasından yararlanılarak aşınma kayıpları belirlenmiştir. Aşınma testlerinde, Buehler Surfmet I makinesinden yararlanışmıştır. Testlerde, 80 mesh su zımparası, $20 \mathrm{~N}$ yük, $50 \mathrm{~m}$ kayma mesafesi, $300 \mathrm{rpm}$ hıza sahip makine parametreleri kullanılmıştır. Kullanılan bant zımpara $920 \mathrm{~mm}$ boyunda ve $100 \mathrm{~mm}$ enindedir. Aşınma testleri, ağırlıksal aşınma kayıpları baz alınarak yüzdelik değerler şeklinde hesaplanmıştır.

\section{Araştırma Sonuçları ve Tartışma}

\subsection{Makro Analizler}

SAE 1020 çeliği, S1 kaynak elektrodu ve ferrokrom ve ferrobor içeren kaynak tozları kullanılarak 4 farklı kaplama elde edilmiştir. Şekil 1, 500 A akım değerlerine bağlı olarak elde edilen kaplamaya ait cüruf, kaynak dikişi ve hazırlanan kaynak tozu görselini temsil etmektedir. Şekil 1'de görüldüğü üzere kaynak tozları homojen büyüklükte ve benzer geometridedir.
Daha önce de belirtildiği üzere kaynak tozları ağırlıkça \% 16 ferrokrom ve \% 2 ferrobor içermekte ve tüm testlerde aynı oran kullanılmaktadır. Kaplama kaynak dikişleri detaylı incelendiğinde ise, $400 \mathrm{~A}$ akım kullanılarak elde edilen kaplamada homojen olmayan bir kaynak dikişi tespit edilmiştir. 450 A kullanılarak elde edilen kaplamada ise nispi olarak daha homojen bir kaynak dikişi elde edilmiştir. 500 A akım kullanılarak elde edilen kaplama da ise en homojen kaynak dikişlerinin varlığ $\breve{1}_{1}$ tespit edilmiştir (Şekil 1). 550 A akım kullanılarak elde edilem kaplama da ise 3 nolu kaplamaya göre daha az homojen olan bir kaynak dikişi tespit edilmiştir. Elde edilen bu farklılıkların, kaynak tozu-cüruf ilişkileri ve ferro alaşımların karakteristiği ile ilgili olduğu düşünülmektedir.

\subsection{Mikroyapı ve Kimyasal Analizler}

Şekil 2-5'de artan akım değerlerine bağlı olarak elde edilen kaplamaların optik mikroskop mikroyapı fotoğrafları verilmektedir. 400-550 A kullanılarak elde edilen kaplamalar mikroyapısal olarak incelendiğinde; matris yapısı olarak 4 kaplamanın da östenit $(\gamma)$ matris yapısında olduğu belirlenmiştir. Matris yapısı dendritik olarak kaynak ilerleme yönüne dik geometride oluşmuştur. Kaplamalarda matris yapısı dışında karbür ve boro-karbür fazları da yer almaktadır. Mikroyapılarda yer alan bu sert fazların, düşük akım kullanılarak yapılan kaplamalarda (400-450 A) tane sinırları etrafinda beyaz renkte sıralandığı ve kaynağın ilerleme yönüne dik olarak mikroyapıda yer aldığı gözlemlenmiştir (Şekil 2-3).

500 A ile yapılan kaplamada (Şekil 4) karbür ve borokarbürlerin mikroyapıda arttığ 1 gözlemlenmiştir. 550 A ile elde edilen kaplamada ise östenit tanelerinin irileştği ve karbür ve boro-karbürlerin artmış olduğu bir mikroyapı tespit edilmiştir (Şekil 5). Kaplamalardaki östenit fazlarının ortalama tane boyut değişimi Şekil 2-5'teki mikroyapı fotoğraflarında görsel olarak verilmektedir.

Kaplamalarda yer alan fazların, XRD analiz sonuçları ile de uyumlu olduğu tespit edilmiştir. Şekil 6'da 500 A ile elde edilen kaplamadan alınan XRD analiz sonuçları yer almaktadır. Ayrıca; literatürde Zahiri vd., 2014; Lin vd., 2014; Yüksel ve Şahin, 2014; Kirchgaßner vd., 2008; ve Berns ve Fischer, 1987 şeklinde yer alan çalışma sonuçları da bu çalışma sonuçları ile paralellik göstermektedir.
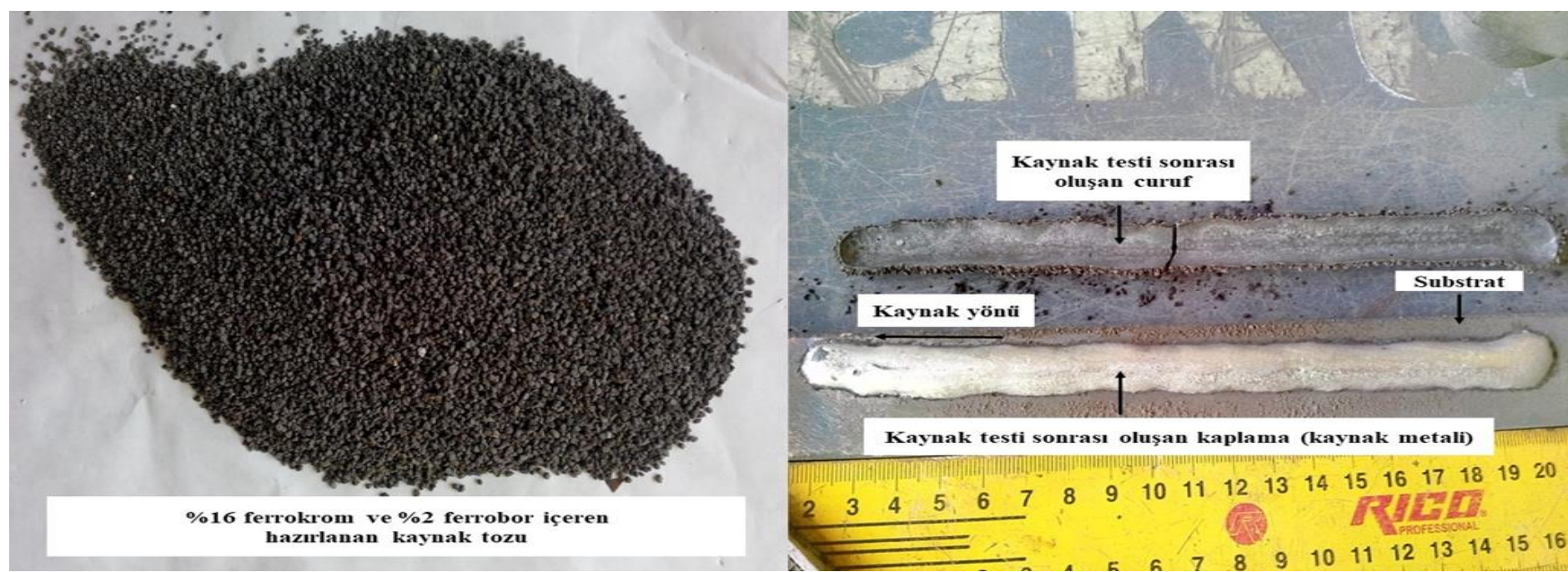
Şekil 1. Hazırlanan kaynak tozu ve 500 A akım kullanılarak elde edilen kaplama ve kaynak sonrası oluşan cüruf görseli.

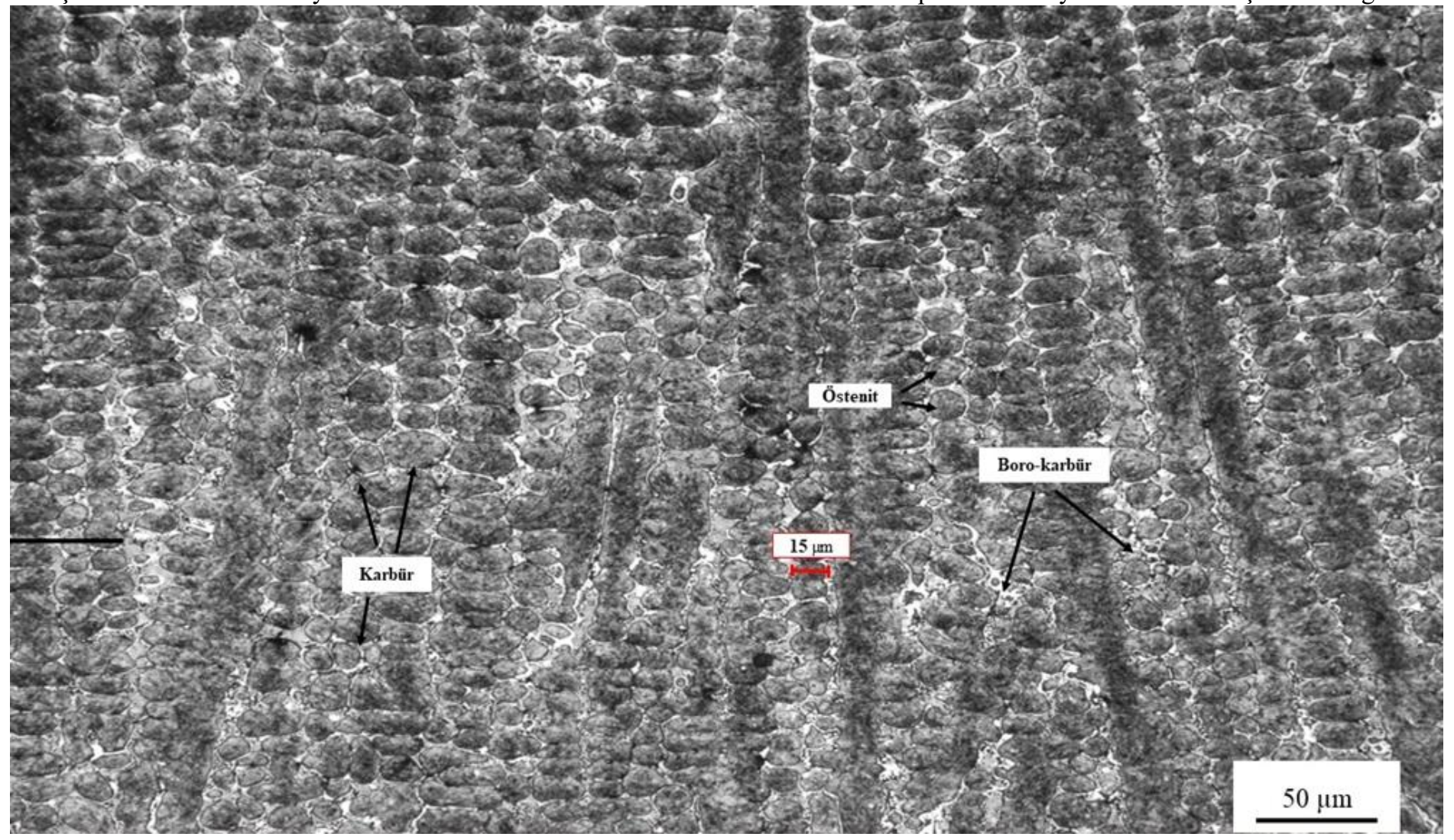

Şekil 2. 400 A kaynak akımı kullanılarak elde edilen kaplamanın optik mikroskop mikroyapı görüntüsü.
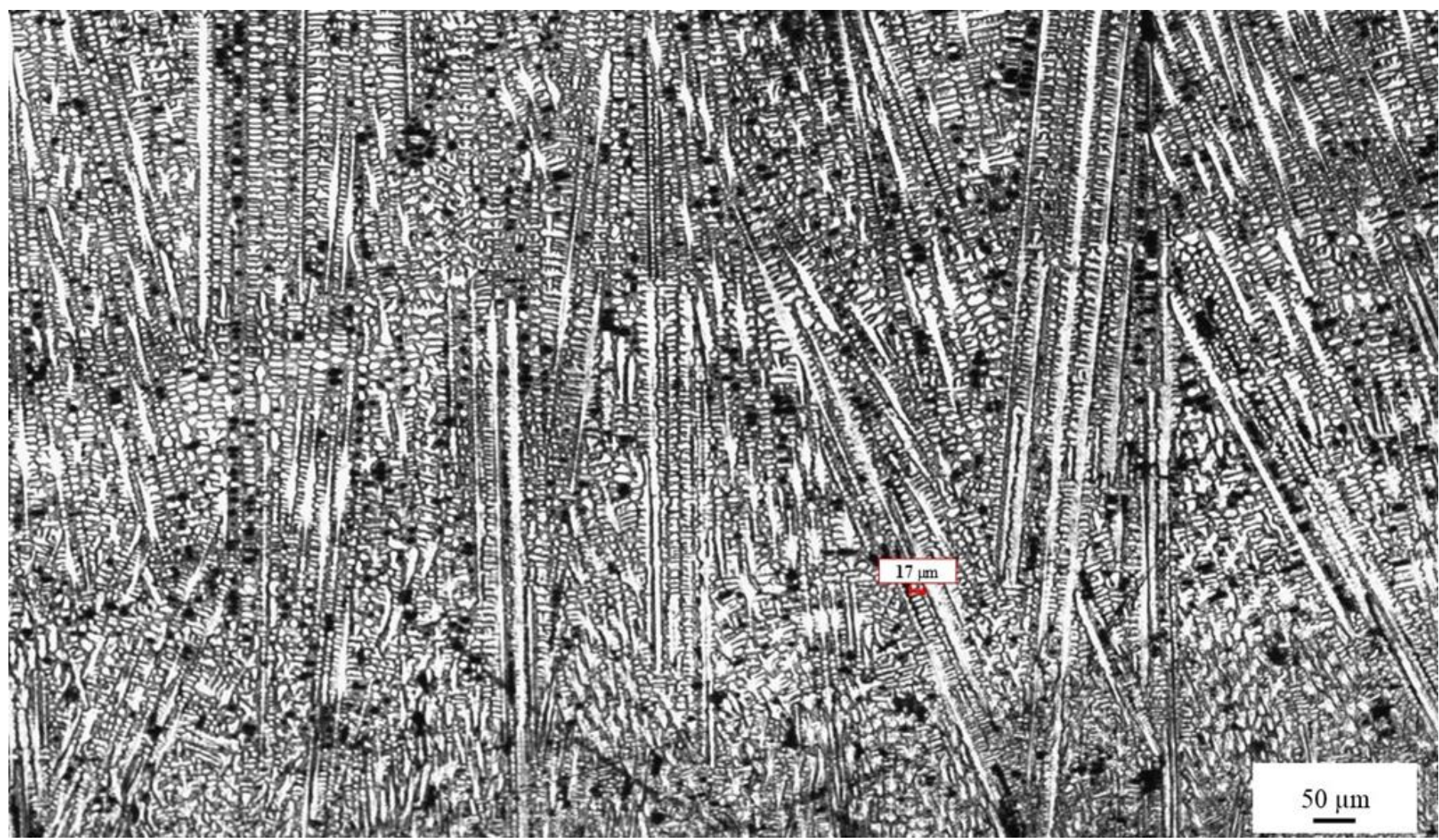
1, 管等
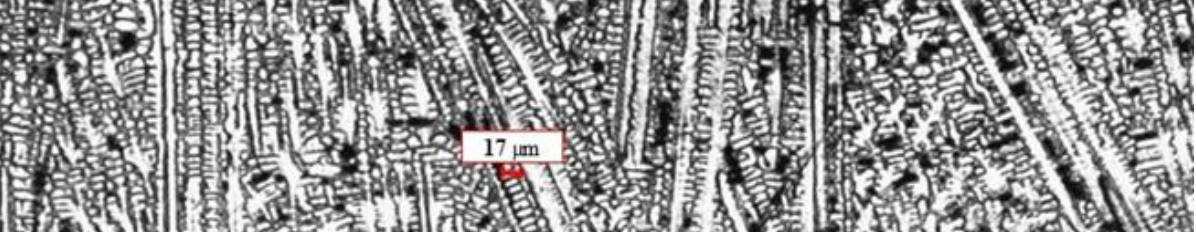
5.

(1) 1.2. 7 1.

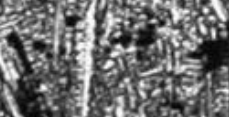

$50 \mu \mathrm{m}$

Şekil 3. 450 A kaynak akımı kullanılarak elde edilen kaplamanın optik mikroskop mikroyapı görüntüsü. 


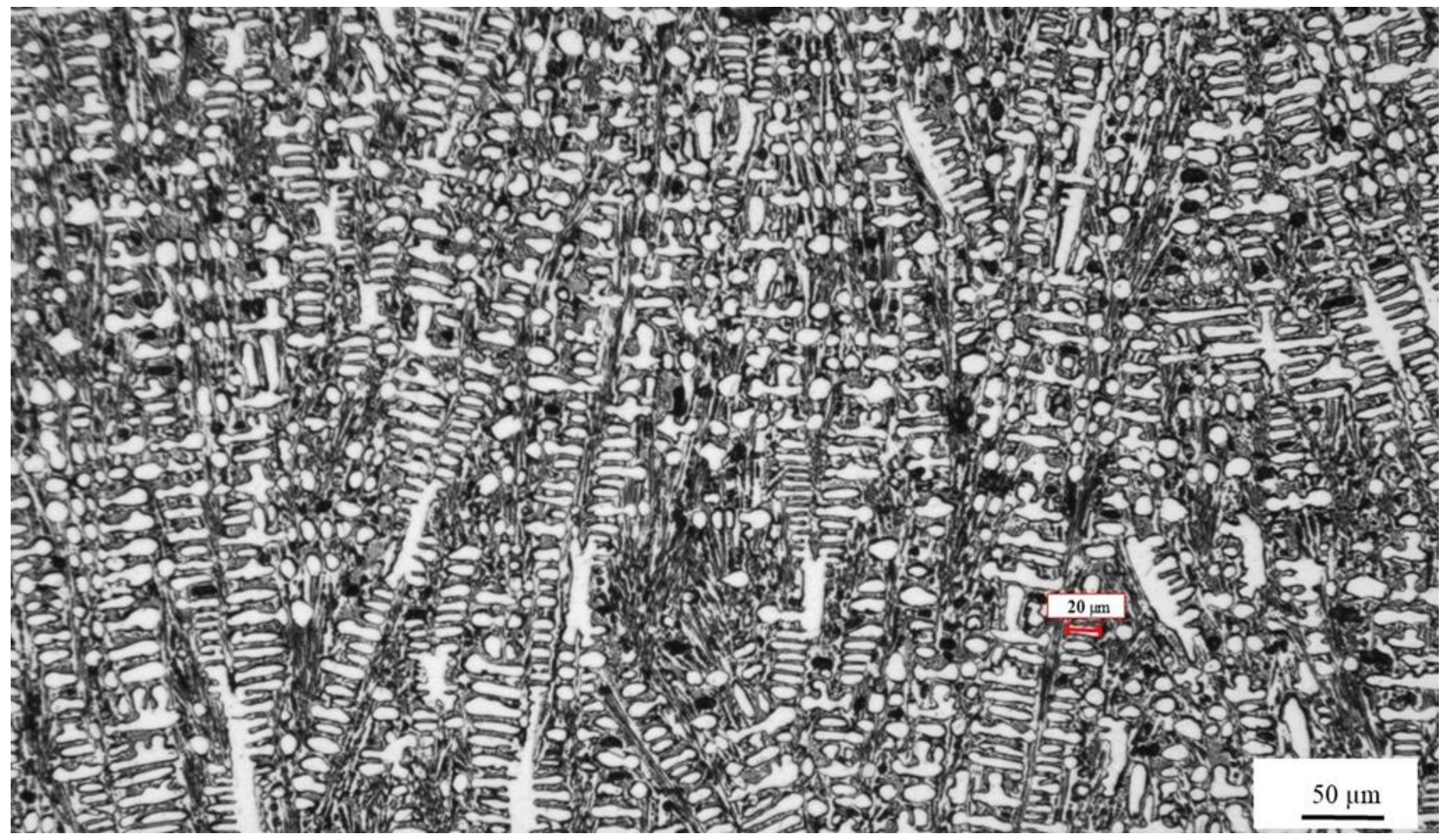

Şekil 4. 500 A kaynak akımı kullanılarak elde edilen kaplamanın optik mikroskop mikroyapı görüntüsü.

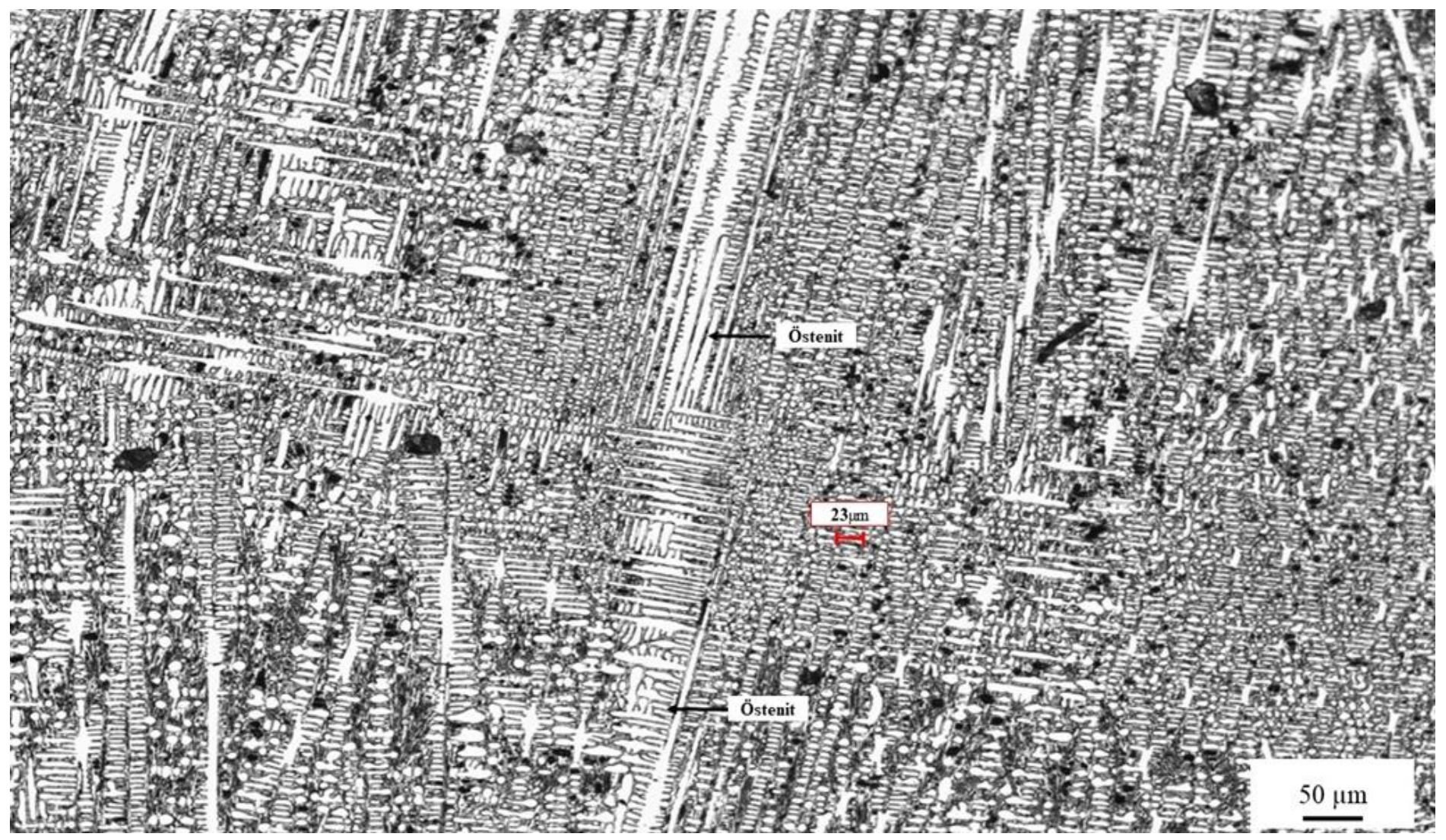


Şekil 5. 550 A kaynak akımı kullanılarak elde edilen kaplamanın optik mikroskop mikroyapı görüntüsü.

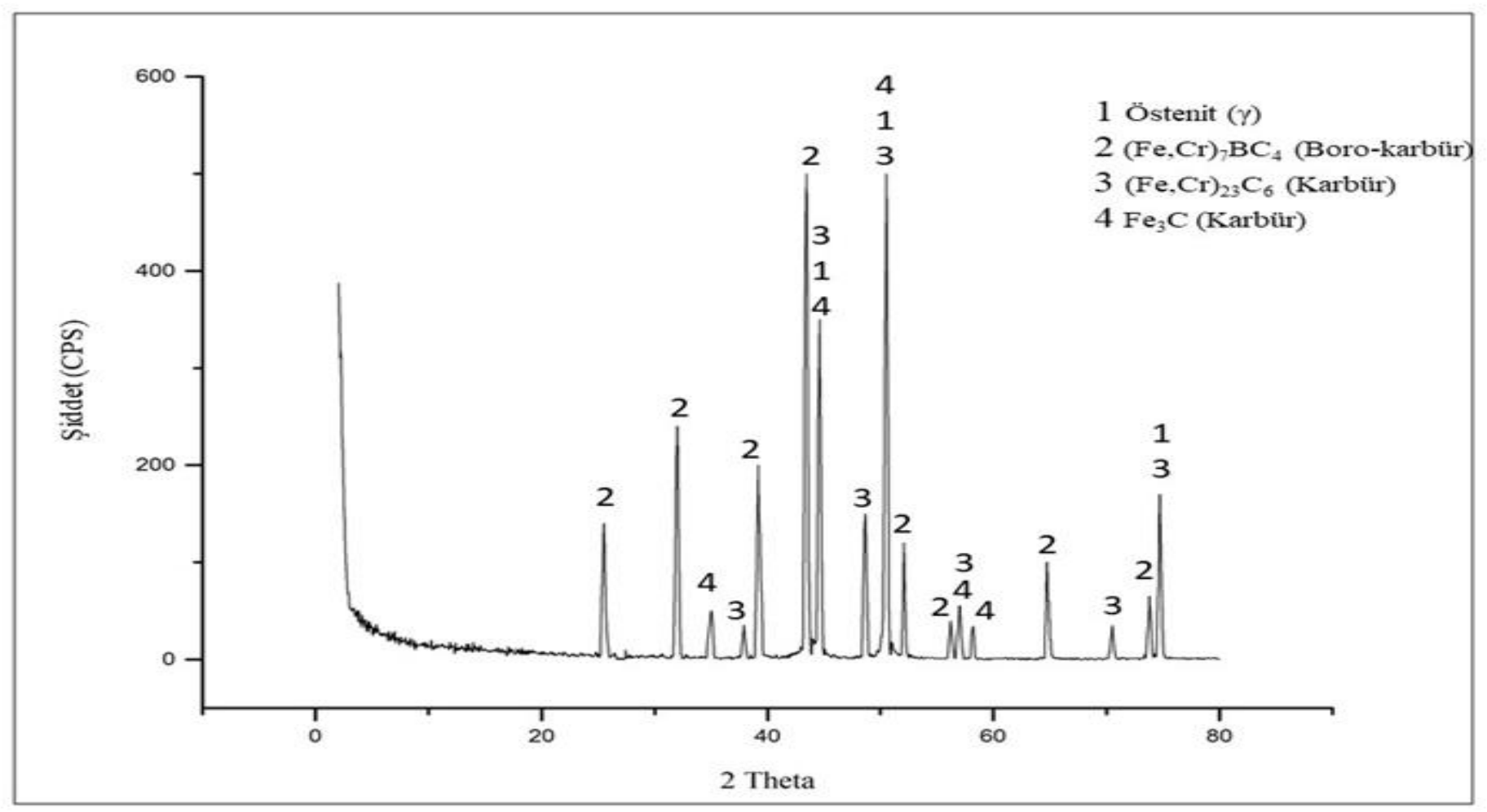

Şekil 6. 500 A kaynak akımı kullanılarak elde edilen kaplamanın XRD analiz sonucu.

400-550 A kaynak akımları kullanılarak elde edilen kaplamaların optik emisyon, SEM-EDX ve EPMA-EDS kimyasal kompozisyon analiz sonuçları Tablo 3'de verilmektedir. Görüldüğü üzere kaynak akımının artması ile ağırlıkça \% 4.25-6.89 oranlarında krom (Cr), \% 0.90-1.10 oranlarında karbon (C) ve 0.35-0.49 oranlarında bor (B)' un kaynak tozlarından kaplamalara geçtiği görülmektedir. Ayrıca, birbirine benzer oranlarda mangan (Mn), molibden (Mo) ve silis (Si)'nde kaplama mikro yapılarında yer aldığı tespit edilmiştir. Kaynak akımının artması, 1sı girdisinin artması neden olarak daha fazla kaynak tozunun tükenmesine neden olmuştur. Böylece, kaplamaya gecen alaşım elementi miktarı artmıştır. Isı girdisinin artması substrat SAE 1020 çeliğinin daha fazla kaynak metalinde çözünmesine ve kaynak dikiş yüksekliğinin kısmı olarak artmasına neden olsa da, kaplamaya gecen alaşaım elementi miktarı akım değerinin artması ile artmıştır. Kaplama geometrisinde meydana gelen bu değişimler, kaynak tozunun temas yüzeyini arttırmış böylece de daha fazla oranda kaynak tozu kaynak testleri esnasında kaplama bölgelerine geçmiştir. 
Tablo 3. Kaplamaların optik emisyon, SEM-EDX ve EPMA-EDS kimyasal kompozisyon analiz sonuçları.

\begin{tabular}{ccccccccc}
\hline $\begin{array}{c}\text { Kaplama test } \\
\text { numunesi }\end{array}$ & $\begin{array}{c}\text { Kaynak akımı } \\
\text { (A) }\end{array}$ & \multicolumn{7}{c}{ Kimyasal kompozisyon (\% ağırlıça) } \\
\cline { 3 - 9 } & & $\mathbf{C r}^{\mathbf{1}}$ & $\mathbf{C}^{\mathbf{2}}$ & $\mathbf{M n}$ & $\mathbf{M o}$ & $\mathbf{S i}^{\mathbf{1}}$ & $\mathbf{B}^{\mathbf{3}}$ & $\mathbf{F e}^{\mathbf{1}}$ \\
\hline 1 & 400 & 4.25 & 0.90 & 1.01 & 0.15 & 0.20 & 0.35 & Kalan \\
\hline 2 & 450 & 4.34 & 0.85 & 0.95 & 0.15 & 0.21 & 0.33 & Kalan \\
\hline 3 & 500 & 6.86 & 1.06 & 1.03 & 0.20 & 0.19 & 0.45 & Kalan \\
\hline 4 & 550 & 6.89 & 1.10 & 1.01 & 0.22 & 0.20 & 0.49 & Kalan
\end{tabular}

(1) : Optik emisyon spektrometresi ile gerçekleştirilen analizleri temsil etmektedir.

(2) : SEM-EDX ile gerçekleştirilen analizleri temsil etmektedir.

(3) : EPMA-EDS ile gerçekleştirilen analizleri temsil etmektedir.

\subsection{Sertlik ve Aşınma Test Sonuçları}

Tablo 4'de kaynak akımına bağlı olarak elde edilen kaplamaların makro sertlik test sonuçları verilmektedir. Görüldüğü üzere 400-500 A akım kullanılarak elde kaplamalarda sertlik doğrusal olarak artmıştır. $550 \mathrm{~A}$ le elde edilen kaplama sertliğinde ise kısmi bir düşüş tespit edilmiştir. Substrat olarak kullanılan SAE 1020 çeliğinin kesitleri düşünüldüğünde, 1S1 girdisinin soğuma hızına etki edeceği çok açıktır. $550 \mathrm{~A}$ ile verilen 1Sı girdisi kaplamanın soğuma hızını yavaşlatarak kaba bir tane yapısına neden olarak sertlikte düşüşe neden olmaktadır. Özellikle östenit tanelerinin irileşmesi sertlikteki kısmı düşüşün nedeni olarak belirlenmiştir. Kaplamalardan elde edilen 44-61 HRC bandındaki sertlik sonuçları, kaynak parametreleri, elektrot, substrat ve kaynak tozu bileşimine bağlı olarak elde edilebildiği ve bu sonuçların literatürdeki çalışma sonuçları ile uyumlu olduğu tespit edilmiştir (Zahiri vd., 2014; Lin vd., 2014; Yüksel ve Şahin, 2014).

Tablo 4. Farklı akım değerlerine bağlı olarak elde edilen kaplamaların makro sertlik test sonuçları.

\begin{tabular}{ccc}
\hline $\begin{array}{c}\text { Kaplama test } \\
\text { numunesi }\end{array}$ & $\begin{array}{c}\text { Kaynak akım } \\
\text { (A) }\end{array}$ & $\begin{array}{c}\text { Sertlik } \\
\text { (HRC) }\end{array}$ \\
\hline $\mathbf{1}$ & 400 & $44 \pm 2$ \\
\hline $\mathbf{2}$ & 450 & $46 \pm 3$ \\
\hline $\mathbf{3}$ & 500 & $61 \pm 3$ \\
\hline $\mathbf{4}$ & 550 & $56 \pm 2$ \\
\hline
\end{tabular}

Kaynak akımına bağlı olarak elde edilen kaplamalardan alınan aşınma kaybı değerleri Şekil 7'de verilmektedir. 400-500 A kullanılarak elde edilen kaplamalarda akımın artması ile aşınma kayıpları azalmaktadır. $550 \mathrm{~A}$ ile elde edilen kaplamada ise $500 \mathrm{~A}$ ile elde edilen kaplamaya göre aşınma kayıplarının kısmi olarak yükseldiği tespit edilmiştir. Bu durum; soğuma hızının düşmesi nedeniyle meydana gelen sertlik düşüşü ile ilişkilendirilmiş̧ir. 500 A kullanılarak elde edilen kaplama, en yüksek aşınma direncine sahip kaplama iken, 400 A ile elde edilen kaplama ise, en düşük aşınma direncine sahip kaplama olmuştur. Kaplamalarda yer alan karbür ve borokarbürler sertlik arţ̧ına neden olarak aşınma direcinin artmasına neden olmaktadır. En yüksek akım ile elde edilen kaplamada ise östenit tanelerinin irileşmesi nedeniyle aşınma direncinde kısmi bir düşüş gözlenmiştir (Lin vd., 2014; Yüksel ve Şahin, 2014; Kirchgaßner vd., 2008).

Kaplamalarin artan akım miktarına bağlı olarak elde edilen

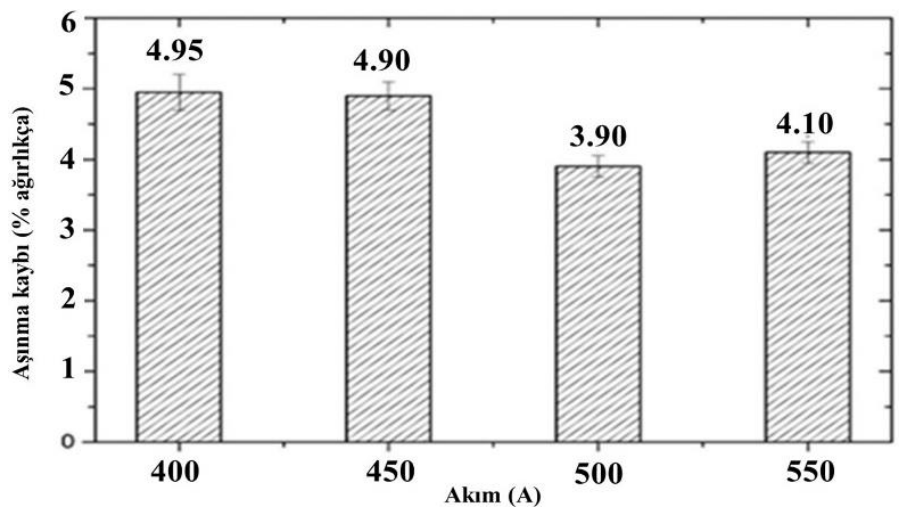

aşınma çizgileri incelendiğinde, genel olarak aşınmaya dirençli aşinma çizgilerinin varlığı tespit edilmiştir. $400 \mathrm{~A}$ ve $450 \mathrm{~A}$ uygulanarak elde edilen kaplamalarda aşınma çizgilerinin sürekli ve kalın bir hat boyunca devam ettiği, bazi süreksiz aşinma çizgilerinin bulunduğu ve krater oyuklarının varlığ 1 tespit edilmiştir. Özellikle 400 A kullanılarak elde edilen kaplamada yoğun sürekli çizikler ve geniş hatlar boyunca devam eden aşınmış yüzey morfolojisi tespit edilmiştir. $500 \mathrm{~A}$ kullanılarak elde edilen kaplamada ise, aşınma çizgilerinin süreksiz ve çok ince morfolojide olduğu gözlemlenmiştir. $\mathrm{Bu}$ kaplamada, aşınmaya direnç gösteren karbür ve boro-karbür gibi yapıların varlı̆ğ nedeniyle krater oyuklarının oluştuğu gözlemlenmiştir. $550 \mathrm{~A}$ ile elde kaplamada ise, $500 \mathrm{~A}$ ile elde edilen kaplamanın 
aşınma davranışına benzer aşınma çizgileri tespit edilmiştir. Ancak, krater oyuklarının 500 A ile elde edilen kaplamaya oranla daha az sayıda olduğu gözlemlenmiştir. Kaplamalarda meydana gelen karbür ve boro-karbür miktarının artması ve ince taneli bir yapı oluşması, sertliğin artmasına ve aşınma kayıplarının azalmasına neden olmaktadır. Bu durum, $500 \mathrm{~A}$ akım kullanılarak elde edilen kaplamalarda yoğun bir şekilde kendini göstermektedir. Özellikle kaplama mikroyapılarında ince taneli karbür ve boro-karbürlerin miktarının artması aşınma direncinin artmasına ve aşınma kayıplarının azalmasına neden olmaktadır (Yüksel ve Şahin, 2014).

Şekil 7. Kaynak akımına bağlı olarak elde edilen kaplamaların aşınma kayıpları.

\section{Sonuç}

Çalışmada, tozaltı kaynak tekniğinde, SAE 1020 çelik substrat, ağırlıkça \% 16 ferrokrom ve \% 2 ferrobor içeren kaynak tozları, S1 kaynak elektrodu ve 400-550 A aralığındaki akım şartları altında kaplama amaçlı kaynak testleri gerçekleştirilmiştir. Kaynak testleri neticesinde;

1- Kaynak akımının artması ile elde edilen kaplamalara kaynak tozundan gecen alaşım elementi miktarının arttığ tespit edilmiştir.

2- $550 \mathrm{~A}$ akım değerinde 1sı girdisinin artması nedeniyle daha kaba bir mikroyapı oluşumu gözlemlenmiştir. Bu durumun, kaplama sertlik ve aşınma özelliklerine negatif etkide bulunduğu tespit edilmiştir.

3- Ferrokrom ve ferrobor içeren kaynak tozları ile gerçekleştirilen testlerde, akım değerinin optimum değerin üzerinde arttırılması veya azaltılması kaynak dikişinin homojenliğinin azalmasına neden olduğu tespit edilmiştir.

4- Ferrokrom ve ferrobor içeren kaynak tozları kullanılarak gerçekleştirilen kaynak testleri neticesinde, optimum kaynak akım değerinin 500 A olduğu ve bu kaynak akım değerinin kaplamanın sertlik ve aşınma özelliklerinin geliştirilmesine katkı sağladığı tespit edilmiştir.

5- Krom, karbon ve bor içeren elementlerle elde edilen kaplama uygulamalarında, kaynak akımı ve substrat geometrisinin kaplama sertlik ve aşınma özelliklerini doğrudan etkilelediği tespit edilmiştir. $\mathrm{Bu}$ doğrultuda, bu tipteki ticari ve akademik uygulamalarda makine parametrelerine ve substrat geometrisine azami dikkat edilmesi önerilmektedir.

\section{Kaynakça}

Oates R., Saitta M.A. (2000), A.M., Welding Handbook, Volume 4 -Materials and Applications, Miami, FL, 33126, American Welding Society.

Civjan S.A., Guihan T., Peterman K. (2020). Testing of oxyacetylene weld strength. Journal of Constructional Steel Research, 168, 105921.

Shrivas S.P., Vaidya S.Y., Khandelwal A.S., Vishvakarma A.K. (2020). Investigation of TIG welding parameters to improve strength. Materials Today: Proceedings, 2020, ISSN 22147853.

Köse C.\& Topal C. (2020). Plazma ark kaynağıyla birleştirilen AISI 410S ferritik paslanmaz çeliğin mikroyapı ve mekanik özelliklerine 1sıl işlemin etkisi. Avrupa Bilim ve Teknoloji Dergisi, (19), 201-212.

Kurtulmuş M. (2018). Effects of Primary Welding parameters on FCAW steel weld form. Avrupa Bilim ve Teknoloji Dergisi, (12), 1-5

Aydın K., Karaağaç İ. (2019). Lazer kaynaklı HSLA sac malzemelerde geri esnemenin deneysel araştırılması. Avrupa Bilim ve Teknoloji Dergisi, (17), 29-37.

Le V.T., Mai D.S. (2020). Microstructural and mechanical characteristics of 308L stainless steel manufactured by gas metal arc welding-based additive manufacturing. Materials Letters, (271), 127791.,

Singh A., Singh R.P. (2020a). A review of effect of welding parameters on the mechanical properties of weld in submerged arc welding process. Materials Today: Proceedings, ISSN 2214-7853.

Singh R.P., Singh A., Singh A. (2020b). Optimization of hardness of weld in submerged arc welding. Materials Today: Proceedings, ISSN 2214-7853.

Sharma L., Kumar J., Chhibber R. (2020). Experimental investigation on surface behaviour of submerged arc welding fluxes using basic flux system. Ceramics International, Volume (46), 6, 8111-8121.

Sailender M., Suresh R., Chandramohan Reddy G., Venkatesh S. (2020). Prediction and comparison of the dilution and heat affected zone in submerged arc welding (SAW) of low carbon alloy steel joints. Measurement, (150), 107084, ISSN 0263-2241,

Suman S., Biswas P., Patel S.K., Singh V.P., Kumar A., Kuriachen B. (2020). Measurement of residual stresses in submerged arc welded P91 steel using surface deformation. Materials Today: Proceedings, (21), 3, 1707-1712.

Srikarun B., Oo H.Z., Petchsang S., Muangjunburee P. (2019). The effects of dilution and choice of added powder on hardfacing deposited by submerged arc welding. Wear, (424-425), 246-254.

Liu X., Xu M., Shi Q., Kang J., Procario J., Hou W., Manohar M. (2019). Analysis of niobium-rich phases in the submerged arc welds of high strength low alloy steel. Materialia, (7), 100340, ISSN 2589-1529.

Zahiri R., Sundaramoorthy R., Lysz P., Subramanian C. (2014). Hardfacing using ferro-alloy powder mixtures by submerged arc welding. Surface and Coatings Technology, (260), 220229.

Lin H., Ying L., Jun L., Binghong L. (2014). Microstructure and mechanical properties for TIG welding joint of high boron Fe-Ti-B alloy. Rare Metal Materials and Engineering, (43), 283-286.

Yüksel N., Sahin S. (2014). Wear behavior-hardnessmicrostructure relation of $\mathrm{Fe}-\mathrm{Cr}-\mathrm{C}$ and $\mathrm{Fe}-\mathrm{Cr}-\mathrm{C}-\mathrm{B}$ based hardfacing alloys. Materials \& Design, (58), pp. 491-498.

Kirchgaßner Badisch M.E., Franek F. (2008). Behaviour of ironbased hardfacing alloys under abrasion and impact. Wear, (265), 772-779.

Berns H., Fischer A. (1987). Microstructure of Fe-Cr -C-B alloys addition of Nb, Ti and B. Metallography, (20), 401-429. 